\section{Físicos, mésons e a política: a dinâmica da ciência na sociedade}

O trabalho descreve a história de fatos científicos, instituições e equipamentos utilizados em laboratórios de pesquisa, associando ciência, sociedade, políticas gerais e relações internacionais. Destaca o processo que levou Lattes, Occhialini, Powell e o grupo de Bristol a descobrirem o méson produzido artificialmente em acelerador de partículas. Acentuando que a institucionalização da física no Rio de Janeiro foi favorecida pelo sucesso de Cesar Lattes na conjuntura após o fim da Segunda Guerra Mundial, aborda a fundação e as atividades do Centro Brasileiro de Pesquisas Físicas (CBPF) e do Conselho Nacional de Desenvolvimento Científico e Tecnológico (CNPq). A tentativa de construir e montar sincrociclotrons exemplifica a aliança de militares, cientistas, políticos, industriais e técnicos do governo em torno do $\mathrm{CBPF} / \mathrm{CNPq}$, visando a produção de energia nuclear e, em segundo plano, o desenvolvimento da ciência. Para demonstrar a complexidade da construção de uma ordem tecnocientífica, o trabalho ultrapassa os marcos cronológicos propostos (1945-56) e apresenta o desfecho dessa microhistória dos aceleradores de partículas do Brasil. Revelando novos arquivos públicos e privados, recorre à lógica do ator-rede e a outras categorias de análise para lidar com a diversidade e a heterogeneidade de elementos mobilizados pelo pesquisador no exercício de sua profissão. Desfaz mitos e examina a ciência inserida em sistemas de poder.

\footnotetext{
Ana Maria Ribeiro de Andrade Tese de doutorado Universidade Federal Fluminense (UFF) Pesquisadora do Museu de Astronomia e Ciências Afins Rua General Bruce, 586 20921-030 Rio de Janeiro - RJ Brasil
}

\section{Palavras, intenções e gestos: os interesses da elite médica - Congresso Nacional dos Práticos (1922)}

O tema deste trabalho é a profissão médica, analisada do ponto de vista histórico e sociológico. Esta tese se detém em um momento de inflexão da organização do trabalho médico no Brasil: o início deste século. Até aquela época, a prática médica guardava as características de profissão liberal, dependente de um único produtor individual de serviços. Assalariamento, especialização, trabalho em equipe e tecnificação eram elementos que soavam estranhos àqueles profissionais. A partir de então, o mercado de trabalho e o conhecimento médico passaram a sofrer profundas transformações. $\mathrm{O}$ movimento de especialização do conhecimento e de tecnificação das atividades do mundo do trabalho, começaram a invadir a prática médica. O Estado, progressivamente, abandonou uma postura contemplativa diante das questōes sociais para assumir um papel de gestor e promotor em diversos ramos da produção e dos serviços, entre os quais destaca-se a saúde.

Este trabalho analisa as palavras, intenções e gestos da elite médica reunida no Congresso Nacional dos Práticos, realizado em 1922, na cidade do Rio de Janeiro, então capital da República. Palavras, na medida em que 45 relatores apresentaram trabalhos manifestando opiniões distintas, e até contrárias, sobre o modo como as alterações, já mencionadas, interferiam em sua identidade profissional e em sua autonomia técnica e econômica. Intenções, pois esta 'elite' profissional, não assumiu uma postura contemplativa diante do que via e vivia. Gestos, porque em meio à conjuntura histórica convulsionada que caracterizou a década de 1920, algumas proposições se transformaram em moções, em tomadas de posição concretas que se manifestaram explicitamente, contrariando, 
por vezes, os interesses dominantes. As polêmicas de 1922 guardam enorme atualidade. O presente no passado pode auxiliar a compreender mais profundamente os dilemas que incidem sobre o trabalho médico hoje.

André de Faria Pereira Neto
Tese de doutorado, 1997
Universidade do Estado do Rio de Janeiro (UERJ)
Instituto de Medicina Social
Av. Brasil, 4036, $6^{\circ}$ andar
$21040-361$ Rio de Janeiro - RJ Brasil

\section{A vida inteira que podia ter sido e não foi: trajetória de um poeta tísico}

Este estudo procura examinar como um indivíduo acometido pela tuberculose se vê, levando-se em consideração a imagem que fazia de si antes da descoberta da doença; a imagem que construiu de si mesmo a partir da condição de doente, $\mathrm{e}$, finalmente, a imagem reelaborada de si que se consolida a partir daquilo que o indivíduo desenvolve como recurso para o trato com a doença e com o mundo circundante.

O objeto de estudo desta tese é a trajetória de vida de um famoso enfermo de tuberculose: Manuel Bandeira (1886-1968). O tratamento deste tema busca contemplar a possibilidade de se reconstruir a voz do enfermo, naquilo que ela possa nos revelar de original na experiência de se estar doente. Nesse sentido, procura reconstruir o processo do fenômeno de adoecimento no que ele explicita os sentimentos e as concepções do enfermo frente à doença.

Para situar a trajetória do poeta, estabelecendo como eixo de abordagem a sua relação com a doença, o trabalho oferece uma visão tanto da evolução. da representação social da tuberculose, quanto da sua construção pelo saber médico-científico. As mudanças de atitude em relação à doença e os elementos conjunturais que influenciam tais transformações são tratados na análise da trajetória de Manuel Bandeira. Pela leitura da obra de Manuel Bandeira, de seus depoimentos pessoais, e de sua correspondência com amigos e familiares busca-se detectar o modo diferenciado de percepção da doença que marcou sua vivência da tuberculose e como ele articula estas diferenças.

$O$ poeta é apresentado como um caso exemplar de reconstrução da identidade, e sua poesia, instrumento de superação da doença, o elemento definidor de uma nova identidade. Através da análise de sua obra poética, podemos acompanhar como Manuel Bandeira produz e reproduz uma representação da tuberculose e observar, também, por outro lado, que a tuberculose e a poesia, a doença e a arte exercem uma influência recíproca na sua trajetória de vida.

$$
\begin{array}{r}
\text { Ângela Pôrto } \\
\text { Tese de doutoramento, 1997 } \\
\text { Instituto de Medicina Social (UERJ) } \\
\text { Av. Brasil, 4036, sala 402 } \\
\text { 21040-360 Rio de Janeiro - RJ Brasil } \\
\text { email:aporto@dcc001.cict.fiocruz.br }
\end{array}
$$

\section{O espelho e o tempo: análise da coleção de obras raras e especiais da Fundação Oswaldo Cruz como fonte de pesquisa para a ciência moderna}

O trabalho investiga o valor do livro raro como fonte de informação para a ciência moderna e elege como objeto de estudo a coleção de obras raras da biblioteca de Manguinhos. Através da revisão de literatura, é realizada uma breve abordagem sobre o livro raro. São feitas recomendações metodológicas para o enfoque de critérios de raridade bibliográfica. O estudo também descreve as condições sob as quais a ciência se desenvolveu no Brasil do início do século. São avaliados os títulos que compõem a coleção de análise como fonte de informação científica e histórica, empregando a análise de citações como indicativo de uso. Com os dados coletados, constata-se o potencial do livro raro como fonte de pesquisa para a ciência moderna.

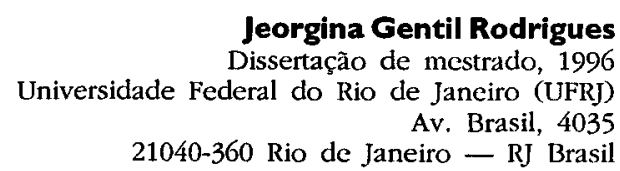

Jeorgina Gentil Rodrigues Dissertação de mestrado, 1996 Av Brasil 4035 21040-360 Rio de Janeiro - RJ Brasil 